\title{
IDENTIFIKASI POTENSI PENYEBAR BENIH TUMBUHAN PADA HUTAN RAWA GAMBUT DALAM RANGKA REGENERASI ALAMI DAN RESTORASI LAHAN GAMBUT PASCA KEBAKARAN
}

\section{Identification of Potential Seed Disperser in Peat Swamp Forest in the Context of Natural Regeneration and Post-Fire Peatland Restoration}

\author{
Rike Puspitasari Tamin ${ }^{1}$, Maria Ulfa ${ }^{1}$, Zuhratus Saleh $^{1}$ \\ ${ }^{1)}$ Fakultas Kehutanan Universitas Jambi, Jl. Raya Jambi-Ma.Bulian KM.15, Mendalo Indah, \\ 36361 \\ E-mail: rikepuspitasari_unja@yahoo.co.id,maria.ulfa@unja.ac.id, \\ zuhratussaleh@ymail.com,
}

Diterima: 03 Maret 2021, Direvisi: 19 Maret 2021, Disetujui: 28 Juli 2021

DOI: 10.31849 /forestra.v16i2.6279

\begin{abstract}
Natural regeneration is a possible option in restoration activities and requires the presence of mother tree and seed dispersing agents. This study aims to identify the seed dispersing agents in Tahura Orang Kayo Hitam and has been carried out for 3 months from June to August 2020. These tree species were obtained by sampling method with a plot size of $20 \times 20 \mathrm{~m}$ determined by a $500 \mathrm{~m}$ long transect. One transect consists of 6 plots and a total of 3 lines so that the total observation plots are 18 plots. All trees with a diameter above $10 \mathrm{~cm}$ were measured and identified. Seed dispersing agents were identified by literature study, photo and discussion with locals. The results indicated that the species found in the study area were spread by wind and wildlife. From the 32 tree species were found, 10 species (32\%) were spread by the wind and 22 species (68\%) were spread by wild animals such as birds, bats and primates. The conclusion is that wind and wildlife are very important in the distribution of tree seeds in burned areas. In addition, the high number of species spread by wildife shows the importance of preserving wildlife in the ecosystem.
\end{abstract}

Keywords: natural regeneration, peat swamp forest, restoration, seed disperser

\begin{abstract}
ABSTRAK
Regenerasi alami merupakan pilihan yang memungkinkan dalam kegiatan restorasi dan membutuhkan keberadaan pohon induk dan penyebar benih yang mampu menyebarkan benih pohon ke seluruh hutan. Penelitian ini bertujuan untuk mengidentifikasi agen penyebar benih berbagai jenis pohon pada Tahura Orang Kayo Hitam dan dilaksanakan selama 3 bulan dari bulan Juni hingga Agustus 2020. Jenis pohon didapatkan dengan metode sampling dengan ukuran plot 20x20 m yang ditentukan dengan cara transek sepanjang $500 \mathrm{~m}$ dari luar hutan ke dalam hutan. Satu transek terdiri dari 6 plot dan total 3 jalur sehingga total plot observasi menjadi 18 plot. Pohon dengan diameter di atas $10 \mathrm{~cm}$ diukur dan diidentifikasi. Agen penyebar benih diidentifikasi melalui studi pustaka, analisis foto dan diskusi dengan pengidentifikasi lokal. Hasil analisis data lapangan menunjukkan bahwa spesies yang ditemukan di wilayah studi disebarkan oleh angin dan satwa liar. Dari 32 jenis pohon yang ditemukan, 10 jenis (32\%) disebarkan oleh angin dan 22 jenis (68\%) oleh satwa liar seperti burung, kelelawar dan primata. Kesimpulan penelitian ini adalah bahwa angin dan satwa liar sangat penting dalam
\end{abstract}


penyebaran benih pohon di area yang terbakar. Selain itu, tingginya jumlah spesies yang disebarkan oleh satwa liar menunjukkan pentingnya pelestarian satwa liar dalam ekosistem untuk mendukung regenerasi hutan.

Kata Kunci : Hutan rawa gambut, penyebar benih, regenerasi alami, restorasi

\section{PENDAHULUAN}

Hutan rawa gambut di Indonesia termasuk yang paling luas di dunia dengan luas sekitar 200.000 km2 (Page, Rieley dan Banks, 2011) tetapi terdegradasi dengan cepat karena berbagai hal seperti kebakaran, logging dan pertanian sehingga tahun 2010 hanya $4 \%$ hutan rawa gambut di Sumatera dan Kalimantan yang dapat dikatakan dalam kondisi yang sangat baik (Miettinen dan Liew, 2010). Padahal hutan rawa gambut merupakan ekositem yang menarik dimana walaupun banyak faktor pembatas seperti keasaman serta kadar nurien yang rendah tapi mempunyai keanekaragaman jenis pohon yang cukup tinggi sekitar 1.300 - 1.500 spesies (Posa, Wijedasa, dan Corlett, 2011; Giesen, Wijedasa, dan Page, 2018).

Hutan yang mengalami kerusakan akibat kebakaran secara alami memiliki kemampuan untuk pulih kembali menuju keseimbangan selama kerusakan akibat kebakaran tersebut tidak lebih besar dari daya lenting (resilience) hutan untuk pulih kembali. Demikian pula hutan rawa gambut yang terdegradasi memiliki kemampuan untuk memulihkan kembali kondisi habitatnya dengan cara suksesi alami. Namun cara ini cenderung memakan waktu yang sangat lama sehingga dibutuhkan usaha manusia memalui suksesi buatan agar dapat menjadikan lahan gambut yang terdegradasi menjadi lebih produktif. Restorasi hutan rawa gambut bukanlah proses yang mudah karena ekosistem ini memiliki kemampuan regenerasi yang rendah khususnya dengan banyaknya gangguan yang terja diseperti kebakaran berulang (Page et al., 2009).

Provinsi Jambi mempunyai hutan rawa gambut yang termasuk dalam kawasan konservasi sebagai Taman Hutan Raya (Tahura) yaitu Tahura Orang Kayo Hitam (Tahura OKH) yang luasnya 18.363,79 ha. Berdasarkan peta landscape Tahura Orang Kayo Hitam tahun 2012 terdapat 5 kelas tutupan lahan yaitu rawa sekunder (10.710,35 ha), rawa primer (18,07 ha), semak belukar (7.394 ha), tanah terbuka (1,53 ha) dan rawa (109,92 ha). Tahura $\mathrm{OKH}$ masih memiliki jenis pohon khas 
ekosistem gambut seperti Jelutung Rawa,

Pulai Rawa dan beberapa spesies pohon lainnya (Tamin, Ufa dan Saleh, 2019).

Tahura OKH terdapat pada dua kabupaten yaitu Kabupaten Muaro Jambi dan Kabupaten Tanjung Jabung Timur. Kawasan Tahura ini didominasi oleh lahan gambut yang sudah terdegradasi parah yang terutama disebabkan kebakaran berulang. Kebutuhan akan restorasi lahan gambut semakin meningkat terutama karena kebakaran hutan di kawasan ini terjadi sering kali padahal di lokasi ini juga sering menjadi target restorasi ekosistem. Kebakaran terakir tahun 2019 bahkan menghancurkan usaha restorasi yang telah dilakukan sebelumnya. Berbagai usaha telah dilakukan dalam melakukan restorasi tetapi sebagian besar terkendala dalam menemukan jenis yang sesuai untuk melakukan restorasi tersebut, mahalnya biaya dan tingkat keselamatan tanaman (survival rate). Biaya untuk tindakan revegetasi lahan gambut untuk satu tahun saja membutuhkan sekitar $11.000 \mathrm{USD} / \mathrm{Ha}$ yang mencakup semua komponen yang dibutuhkan mulai dari persiapan sampai monitoringnya (Graham, Turjaman dan Page, 2013).
Gambaran biaya yang mahal tersebut menjadi alasan untuk regenerasi alami menjadi pilihan yang paling mungkin dalam restorasi hutan rawa gambut. Untuk Tahura OKH sendiri berbagai penelitian telah dilakukan terkait dengan regenerasi alami. (Tamin, Ulfa, dan Saleh, 2018) mengidentifikasi beberapa jenis yang tumbuh pada lokasi bekas terbakar kemudian dilanjutkan penelitian (Tamin, Ulfa, dan Saleh, 2019) yang mengidentifikasi potensi pohon induk yang ada di lokasi Tahura OKH ini dan menemukan setidaknya 25 spesies dan 52 individu pohon dan sebagiannya merupakan pohon induk potensial.

Salah satu variabel penting dalam regenerasi alami di hutan gambut adalah bagaimana tumbuhan tersebut menyebar dan disebarkan oleh apa. (Wijedasa et al., 2020) mengungkapkan bahwa burung, mamalia dan angin merupakan agen penyebar utama dari anakan yang tumbuh sebagai regenerasi alami di hutan rawa gambut di bekas hutan tanaman di Sumatera Selatan. Setelah melakukan berbagai kajian pustaka terlihat bahwa untuk Tahura $\mathrm{OKH}$, data mengenai penyebar biji (seed disperser) dan 
kaitannya dengan regenerasi alami hutan rawa gambut belum dilakukan. Isu ini menjadi perhatian tim peneliti untuk melakukan penelitian terkait hal tersebut di Tahura OKH Provinsi Jambi.

Pengetahuan mengenai jenis yang tumbuh di hutan rawa gambut serta potensinya sebagai pohon induk merupakan hal yang bermanfaat secara nyata terhadap usaha restorasi lahan gambut terutama pasca kebakaran hebat 2015. Selanjutnya adalah melihat bagaimana regenerasi alami terjadi dengan melihat bagaimana spesies yang ada di hutan rawa gambut tersebar sehingga dapat dilihat prospek regenerasinya. Penelitian ini bertujuan untuk melakukan identifikasi dan mempelajari agen penyebar tumbuhan di Tahura $\mathrm{OKH}$ dan kaitannya dengan regenerasi alami Tahura OKH.

\section{METODE PENELITIAN}

Penelitian ini terlaksana dalam 7 bulan yang dimulai dari Maret-Oktober 2020. Penelitian ini dilaksanakan di Tahura Orang Kayu Hitam Provinsi Jambi kemudian analisis data akan dilakukan di Laboratorium Silvikultur serta Herbarium Fakultas Kehutanan Universitas Jambi
(Fahutan UNJA). Jika ada spesimen herbarium akan didentifikasi di herbarium terstandar dan hasilnya akan disimpan di Herbarium Fahutan UNJA.

Alat yang digunakan sepanjang proses pelaksanaan penelitian diantaranya adalah gunting stek, plastik, kertas label, benang wol, pensil, kertas koran, galah, ph meter, hygrometer, Global positioning system (GPS), kamera, tali raffia, pita ukur, serta laptop untuk menganalisis data. Bahan yang dipakai untuk pengumpulan sampel yaitu tally sheet, material yang memiliki ciri khas seperti, buah, biji dan lainnya, polybag, tanah topsoil, pasir, kompos serta alkohol $70 \%$.

Pengambilan sampel di lapangan dengan menggunakan metode eksplorasi lapangan. Cara peletakan unit contohnya menggunakan cara sistematik dengan posisi 500 meter kearah hutan dan 500 m ke arah luar hutan dimana titik awalnya adalah tepi hutan. Ke arah hutan mewakili area yang tidak terkena kebakaran sedangkan ke luar hutan mewakili area bekas terbakar. Satu jalur akan memuat 6 plot pengamatan dengan panjang 500 meter dan dilakukan sebanyak 6 jalur. Plot pengamatan berukuran $\quad 20 \quad m \quad x \quad 20 \quad m$ sehingga 
didapatkan total luasan area contoh adalah seluas 1,44 H. Setiap pohon dengan diameter diatas $2 \mathrm{~cm}$ diukur dan dijadikan sebagai data penelitian. Foto diambil sedemikian rupa sehingga dapat menjadi alat identifikasi melalui foto di lembaga pengidentifikasi tumbuhan (herbarium). Agen penyebar diketahui dengan melakukan pengamatan lapangan, kajian pustaka secara mendalam, serta bertanya kepada ahli botani dan pemandu lapangan yang berkompetensi dalam menjawab pertanyaan yang berkaitan dengan penyebaran biji tumbuhan.

Struktur komunitas yang dianalisis adalah kerapatan, kerapatan relatif, frekuensi, frekuensi relatif, dominansi dan dominansi relatif (Indriyanto, 2006). Penentuan indeks keanekaragaman jenis pada penelitian ini menggunakan indeks Shannon-Wiener dihitung dengan rumus :

$$
\mathrm{H}^{\prime}=\Sigma_{t=1}^{s}(p i) \ln p i
$$

Dimana :

$\mathrm{H}=$ indeks diversitas Shannon

$\mathrm{S}=$ jumlah spesies

$\mathrm{Pi}=$ proporsi jumlah individu ke-I

$$
\mathrm{Ln}=\log \text { natural }
$$

Indeks keanekaragaman

mengeluarkan hasil dalam bentuk angka yang berkisar antara 0 sampai diatas 3 . Definisi dari angka tersebut adalah $\mathrm{H}^{\prime} \leq 1=$ keanekaragaman kecil, $\quad 1 \leq \mathrm{H}^{\prime} \leq 3=$ keanekaragaman sedang, $\mathrm{H}^{\prime}>3=$ keanekaragaman tinggi dan kestabilan komunitas tinggi.

Indeks Kemerataan ShannonWiener juga dihitung dan dianalisis. Indeks ini didekati dengan definisi angka 0-1 dimana semakin dekat angka ke 1 maka komunitas tersebut semakin stabil (Magurran, 2013). Selanjutnya indeks kekayaan spesies juga dihitung erdasarkan indeks margaleff (Magurran, 2013).

Data penyebar benih akan dianalisis secara deskriptif dengan mengacu kepada studi literatur yang memuat hasil penelitian dan data maupun informasi penyebar benih yang ada. Analisis ini mengacu pada metode yang digunakan (Wijedasa et al., 2020). Hubungan penyebar benih dan kondisi regenerasi akan di dianalisisis secara deskriptif berdasarkan komposisi spesies serta jaraknya dengan tegakan hutan rawa gambut alami yang tersisa setelah kebakaran hutan. 


\section{HASIL DAN PEMBAHASAN}

Penelitian terhadap jenis tumbuhan pohon yang hidup di Tahura OKH telah dilakukan dan mendapatkan hasil sebanyak 21 famili tumbuhan yang terdiri atas 32 spesies pohon (Tabel 2 ). Selanjutnya jika dipisahkan berdasarkan familinya, maka terlihat bahwa Dipterocarpaceae menjadi famili dengan jumlah jenis paling banyak yaitu sebanyak 6 jenis. Famili Dipterocarpaceae dikenal sebagai penghasil jenis yang menghasilkan kayu dengan kualitas yang sangat baik dan sering ditemukan ada daerah dataran rendah termasuk juga daerah gambut.
Hasil pengamatan di lapangan terhadap penyebar benih dari berbagai jenis pohon yang ada di daerah yang masih punya vegetasi menunjukkan bahwa terdapat 2 dari 4 penyebar benih potensial yang menyebarkan 32 jenis pohon yang ditemukan. Penyebar benih tersebut adalah angin dan satwa liar. Data lapangan menunjukkan bahwa satwa liar menyebarkan 22 jenis tumbuhan sedangkan angin menyebarkan 10 jenis tumbuhan (Gambar 6).

Tabel 2. Komposisi Jenis Pohon diTahura OKH

\begin{tabular}{clll}
\hline No. & Family & Spesies & Nama Lokal \\
\hline 1 & Anacardiaceae & Gluta renghas & Rengas \\
2 & Anacardiaceae & Mangifera quadrifida & Rengas Sumpung \\
3 & Anacardiaceae & Melanorrhea wallichii & Pelakok \\
4 & Annonaceae & Drepananthus biovulatus & Pisang-Pisang \\
5 & Annonaceae & Xylopia altisima Bl. & Jangkang \\
6 & Dipterocarpaceae & Anisoptera sp. & Mersawa \\
7 & Dipterocarpaceae & Shorea ovata & Merawan \\
8 & Dipterocarpaceae & Shorea palembanica & Meranti Lempung \\
9 & Dipterocarpaceae & Shorea sp. & Meranti \\
10 & Dipterocarpaceae & Shorea sp1 & Meranti Batu \\
11 & Dipterocarpaceae & Shorea teysmanniana & Meranti Bunga \\
12 & Apocynaceae & Dyera lowii & Jelutung \\
13 & Clusiaceae & Callophyllum sp. & Bintangur \\
14 & Dilleniaceae & Dillenia eximia & Simpur \\
15 & Ebenaceae & Diospyros mangiayi & Arang-Arang \\
16 & Elaeocarpaceae & Elaeocarpus griffithi & Kelat Merah \\
\hline
\end{tabular}




\begin{tabular}{llll}
\hline No. & Family & Spesies & Nama Lokal \\
\hline 17 & Euphorbiaceae & Baccaurea sp. & Asam-Asam \\
18 & Fabaceae & Archidendron fagifolium & Kayu Pagar \\
19 & Hypericaceae & Cratoxylon arborescens & Gerunggang \\
20 & Lauraceae & Alseodaphne sp. & Medang Lendir \\
21 & Lauraceae & Litsea sp. & Medang \\
22 & Loganiaceae & Fagraea gigantea & Bulian Kasang \\
23 & Moraceae & Ficus hispida & Aro \\
24 & Myristicaceae & Knema cinerea & Darah-Darah \\
25 & Myrtaceae & Syzygium littoralis & Kelat Putih \\
26 & Myrtaceae & Syzygium sp. & Kelat \\
27 & Rutaceae & Melicope lunu-ankenda & Melicope \\
28 & Sapotaceae & Palaquium sp. & Nyato Babi \\
29 & Tetrameristaceae/Theaceae & Tetramerista glabra & Punak \\
30 & Celastraceae & Lophopetalum javanicum & Perupuk \\
31 & Rhizoporaceae & Gynotroches axillaris & Mato Keli \\
32 & Fabaceae & Koompassia sp. & Kempas \\
\hline & 21 Famili & 32 Spesies & \\
\hline
\end{tabular}

Tabel 3. Jenis Pohon yang Disebarkan Satwa Liar

\begin{tabular}{clcc}
\hline No. & Spesies & Burung & Mamalia \\
\hline 1 & Gluta renghas & $\sqrt{ }$ & \\
2 & Mangifera quadrifida & & $\sqrt{ }$ \\
3 & Melanorrhea wallichii & $\sqrt{ }$ \\
4 & Drepananthus biovulatus & & \\
5 & Xylopia altisima Bl. & $\sqrt{ }$ \\
6 & Callophyllum sp. & $\sqrt{ }$ & \\
7 & Dillenia eximia & $\sqrt{ }$ & $\sqrt{ }$ \\
8 & Diospyros mangiayi & & \\
9 & Elaeocarpus griffithi & & $\sqrt{ }$ \\
10 & Baccaurea sp. & $\sqrt{ }$ & \\
11 & Archidendron fagifolium & $\sqrt{ }$ \\
12 & Alseodaphne sp. & $\sqrt{ }$ & \\
13 & Litsea sp. & $\sqrt{ }$ & \\
14 & Fagraea gigantea & & \\
15 & Ficus hispida & $\sqrt{ }$ & \\
16 & Knema cinerea & $\sqrt{ }$ & \\
17 & Syzygium littoralis & $\sqrt{ }$ & $\sqrt{ }$ \\
18 & Syzygium sp. & Melicope lunu-ankenda &
\end{tabular}




\begin{tabular}{clcc}
\hline No. & Spesies & Burung & Mamalia \\
\hline 20 & Palaquium sp. & & $\sqrt{ }$ \\
21 & Tetramerista glabra & $\sqrt{ }$ & $\sqrt{ }$ \\
22 & Gynotroches axillaris & $\sqrt{ }$ &
\end{tabular}

Lebih lanjut pada Gambar 1 diperlihatkan bahwa bahwa dari 68\% (22 jenis) yang disebarkan oleh satwa liar tersebut bisa dibagi lagi sesuai kelas dari satwa liar. Kelas yang mengacu ada tingkatan takson secara umum dibagi menjadi dua saja pada penelitian ini yaitu burung dan mamalia. Dari Tabel 3 secara jelas terlihat bahwa 12 jenis disebarkan burung, 10 jenis disebarkan mamalia sedangkan 1 jenis disebarkan oleh keduanya (burung dan mamalia). Penyebar benih sangat dibutuhkan oleh pohon karena sedikit jenis pohon yang mampu tumbuh berkembang dekat dengan induknya. Jarak 100-150 m antara pohon induk dan posisi benih terpencar dianggap paling ideal untuk keberlangsungan regenerasi suatu spesies pohon terutama pada daerah yang terfragmentasi (Hewitt dan Kellman, 2002)

Kehadiran satwa liar Monyet Ekor Panjang di lokasi penelitian seperti pada Gambar 2 ternyata bermanfaat bagi penyebaran benih tumbuhan dan secara langsung berpengaruh terhadap proses regenerasi alami di hutan tersebut. (Ilham, Rizaldi, Nurdin, \& Tsuji, 2017; Tsuji \& Su, 2018) menemukan di lapangan bahwa monyet ekor panjang terbukti sangat potensial sebagai agen penyebar benih bagi tumbuhan terutama pohon buah yang menjadi pakan mereka.

Indeks Keanekaragaman, Indeks Kemerataan dan Indeks Kekayaan Spesies telah dihitung dan disajikan pada Tabel 4 . Jika melihat dari indeks keanekaragaman yang dihitung maka terlihat bahwa keanekaragaman tumbuhan yang ditemukan termasuk daalam kategori keanekaragaman tinggi. Selanjutnya indeks kemerataan menunjukkan nilai yang tinggi sehingga dapat disimpulkan bahwa spesies yang ditemukan tersedia dan populasinya merata. Begitu juga nilai indeks kekayaan mendapatkan angka yang menunjukkan indeks kekayaan tumbuhan di lokasi penelitian tinggi. Ketiga indeks yang dihitung ini menunjukkan bahwa keanekaragaman tumbuhan yang tersedia di lokasi penelitian berada dalam kondisi baik 
dan sangat potensial untuk memperkuat peluang regenerasi alami yang terjadi.

Tabel 3. Indeks Keanekaragaman, Kemerataan dan Kekayaan Spesies di Lokasi Penelitian

\begin{tabular}{lll}
\hline Indeks & Indeks & Indeks \\
Keanekaragaman & Kemerataan & Kekayaan \\
Shannon-Wiener & Shannon- & Margalef (D) \\
$\left(\mathrm{H}^{\prime}\right)$ & Wiener $(\mathrm{E})$ & \\
\hline 3,34 & 0,96 & 7,6 \\
\hline Tinggi & Tinggi & Tinggi \\
\hline
\end{tabular}

\section{Penyebar Benih}

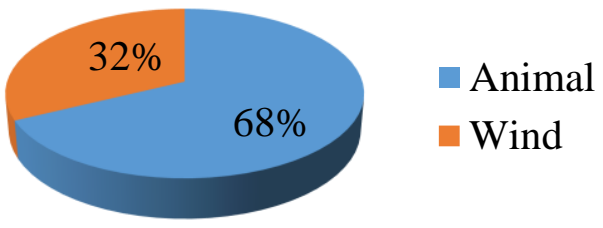

Gambar 1. Persentase Spesies yang Disebarkan Oleh Penyebar Benih

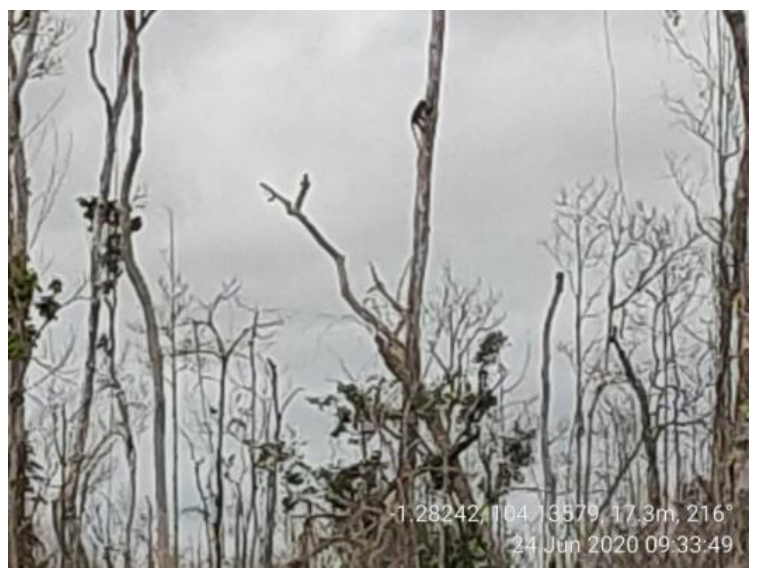

Gambar 2. Monyet ekor panjang (Macaca fascicularis) di Tahura OKH
Di sisi lain, 10 jenis yang disebarkan oleh angin ternyata diisi oleh jenis dari famii Dipterocarpaceae sebanyak 6 jenis. Spesies pohon dari famili Dipterocarpaceae diketahui sangat membutuhkan angin karena benihnya yang bersayap sehingga dapat terbang menjauhi pohon induknya dan mampu tumbuh berkembang (Suzuki dan Ashton, 1996). Jenis terkenal lainnnya dari hutan rawa gambut seperti Dyera lowii (jelutung rawa) juga jenis lokal seperti Pisang-pisang dan Kempas (Tabel 5) juga termasuk kelompok tumbuhan yang disebarkan angin.

Tabel 5. Jenis tumbuhan yang disebarkan Angin

\begin{tabular}{clc}
\hline No & \multicolumn{1}{c}{ Species } & Penyebar Benih \\
\hline 1 & Anisoptera $\mathrm{sp}$. & Angin \\
2 & Shorea ovata & Angin \\
& Shorea & Angin \\
3 & palembanica & Angin \\
4 & Shorea $\mathrm{sp}$. & Angin
\end{tabular}

Shorea

\begin{tabular}{cll}
6 & teysmanniana & Angin \\
7 & $\begin{array}{l}\text { Dyera lowii } \\
\text { Cratoxylon }\end{array}$ & Angin \\
8 & $\begin{array}{l}\text { arborescens } \\
\text { Lophopetalum }\end{array}$ & Angin \\
9 & javanicum & Angin \\
10 & Koompassia $\mathrm{sp}$. & Angin \\
\hline
\end{tabular}


Beberapa literatur (Blackham,

Webb, \& Corlett, 2014; Wijedasa et al., 2020) secara konsisten menyebutkan bahwa penyebaran benih oleh angin dan satwa liar merupakan sistem yang baik bagi regenerasi hutan pasca kebakaran secara alami. Hal ini dikarenakan kemampuan angin dan satwa liar membawa benih jauh dari pohon induknya sehingga dapat disebarkan pada areal yang luas.

\section{KESIMPULAN DAN SARAN}

\section{A. Kesimpulan}

Penelitian ini mendapatkan kesimpulan bahwa angin dan satwa liar teridentifikasi menjadi penyebar benih yang potensial di lokasi penelitian. Keberadaan angin dan satwa liar menjadi perhatian karena fungsinya untuk membantu proses regenerasi alami hutan rawa gambut. Hal ini terkonfirmasi dari 32 spesies tumbuhan (pohon) yang tergabung dalam 21 famili yang ditemukan pada lokasi penelitian.

\section{B. Saran}

Saran yang bisa dilakukan untuk penelitian di masa depan di lokasi ini diantaranya adalah setiap buah dari pohon yang ada bisa dikumpulkan dan dianalisis untuk memperkuat kesimpulan penelitian.

UCAPAN

TERIMA

KASIH

(Acknowledgement)

Penelitian ini sepenuhnya didanai oleh DIPA PNBP LPPM Skema Penelitian Gambut Universitas Jambi Tahun Anggaran 2020 Nomor: SP DIPA023.17.2.677565/2020 Tanggal 27

Desember 2019 sesuai dengan Surat Perjanjian Kontrak Penelitian Nomor: 452/UN21.18/PG/SPK/2020 Tanggal 20 April 2020.

\section{DAFTAR PUSTAKA}

Blackham, G. V, Webb, E. L., dan Corlett, R. T. 2014. Natural regeneration in a degraded tropical peatland, Central Kalimantan, Indonesia: Implications for forest restoration. Forest Ecology and Management, 324, 8-15.

Giesen, W., Wijedasa, L. S., dan Page, S. E. 2018. Unique Southeast Asian peat swamp forest habitats have relatively few distinctive plant species.

Graham, L. L. B. B., Turjaman, M., dan Page, S. E. 2013. Shorea balangeran and Dyera polyphylla (syn. Dyera lowii) as tropical peat swamp forest restoration transplant species: Effects of mycorrhizae and level 
of disturbance. Wetlands Ecology and Management, 21(5), 307-321. https://doi.org/10.1007/s11273-013-9302$\mathrm{x}$.

Ilham, K., Rizaldi, Nurdin, J., dan Tsuji, Y. 2017. Status of urban populations of the long-tailed macaque (Macaca fascicularis) in West Sumatra, Indonesia. Primates, 58(2), 295-305. https://doi.org/10.1007/s10329-016-05881

Indriyanto. 2006. Ekologi hutan. Jakarta: Bumi Aksara.

Magurran, A. E. 2013. Measuring biological diversity. John Wiley \& Sons.

Miettinen, J., dan Liew, S. C. 2010. Degradation and development of peatlands in Peninsular Malaysia and in the islands of Sumatra and Borneo since 1990. Land Degradation \& Development, 21(3), 285-296.

Page, S. E., Rieley, J. O., dan Banks, C. J. 2011. Global and regional importance of the tropical peatland carbon pool. Global Change Biology, 17(2), 798-818.

Page, S., Hosciło, A., Wösten, H., Jauhiainen, J., Silvius, M., Rieley, J. dan Vasander, H. 2009. Restoration ecology of lowland tropical peatlands in Southeast Asia: current knowledge and future research directions. Ecosystems, 12(6), 888-905.

Posa, M. R. C., Wijedasa, L. S., dan Corlett, R.
T. (2011). Biodiversity and conservation of tropical peat swamp forests. BioScience, 61(1), 49-57.

Suzuki, E., dan Ashton, P. 1996. Sepal and nut size ratio of fruits of Asian Dipterocarpaceae and its implications for dispersal. Journal of Trop. Ecol 12(6): 853-870.

https://doi.org/10.1017/S02664674000101 29.

Tamin, R. P., Ulfa, M., dan Saleh, Z. 2018. Komunitas Tumbuhan Pada Habitat Kantong Semar (nepenthes spp.) di Tahura Sekitar Tanjung Pasca Kebakaran Hutan. Jurnal Ilmiah Ilmu Terapan Universitas Jambi| JIITUJ|, 2(1), 25-31. https://doi.org/https://doi.org/10.22437/jiit uj.v2i1.5646

Tamin, R. P., Ulfa, M., dan Saleh, Z. 2019. Identifikasi Potensi Pohon Induk Pada Tegakan Tinggal Taman Hutan Raya Orang Kayo Hitam Pasca Kebakaran Hutan. Jurnal Ilmiah Ilmu Terapan Universitas Jambi| JIITUJ|, 3(1), 10-17.

Tsuji, Y., dan Su, H. H. 2018. Macaques as Seed Dispersal Agents in Asian Forests: A Review. International Journal of Primatology, 39(3), 356-376. https://doi.org/10.1007/s10764-018-00457

Wijedasa, L. S., Vernimmen, R., Page, S. E., Mulyadi, D., Bahri, S., Randi, A., dan 
Hooijer, A. 2020. Distance to forest, mammal and bird dispersal drive natural regeneration on degraded tropical peatland. Forest Ecology and Management, 461, 117868. 